\title{
A temporary forward head posture decreases function of cervical proprioception
}

\author{
Sun-Young Ha', Yun-Hee Sung, ${ }^{1,2 * *}$ \\ 'Department of Physical Therapy, Graduate School, Kyungnam University, Changwon, Korea \\ ${ }^{2}$ Department of Physical Therapy, College of Health Sciences, Kyungnam University, Changwon, Korea
}

Increased use of smartphones can cause abnormal alignment of head and neck, resulting in forward head posture (FHP). This can lead to change in the structures and function of the cervical vertebrae. The purpose of this study was to determine the impact on deep neck flexor muscles, proprioception, vestibular function, and balance of subjects with induced FHP by using smartphone. Twenty-two healthy persons were randomly divided into two groups. The FHP group maintained a craniovertebral angle (CVA) of $\angle 49^{\circ}$ and a normal head posture group maintained a CVA of $>50^{\circ}$ watching the smartphone for $40 \mathrm{~min}$. We measured the area of the longus colli and longus capitis muscles, cervi- cal joint position sense, Romberg test, subjective visual vertical test, and subjective visual horizontal test. There was no significant difference in the deep neck flexor muscles, vestibular function, and static balance between the groups. However, there was a significant difference in the cervical proprioception $(P<0.05)$. Proprioception may be considered to be the most influential factor in induced FHP by smartphone viewing.

Keywords: Forward head posture, Proprioception, Vestibular function, Static balance

\section{INTRODUCTION}

The rapid development of information and communication technology has increased the use of computers and smartphones (Eltayeb et al., 2009; Larsson et al., 2007). When using a smartphone, a user tends to angle their head and neck more forward than when they view a traditional video display (Straker et al., 2008). Thus, phone users maintain an abnormal alignment of the head and neck (Kim and Kim, 2019). The most common problem with smartphone use is forward head posture (FHP) and rounded shoulders (Kang et al., 2012). FHP is defined as $\geq 5 \mathrm{~cm}$ in horizontal distance between the tragus of the ear and the posterior angle of acromion in a standing position. It is also accompanied by flexion of the lower cervical vertebrae and hyper extension of the upper cervical vertebrae (Braun and Amundson, 1989; Hanten et al., 1991). FHP can cause neck pain, leading to decreased movement of the cervical vertebrae and changes in neck muscle func- tion (Burgess-Limerick et al., 1998; Lee, 2016).

FHP moves the body's center-of-gravity forward, thereby inducing mechanical deformation of the joints and vertebrae and muscles involved in postural control (Lee and Jeong, 2001). The deep neck flexor muscles in the cervical vertebrae play an important role in stabilizing the cervical spine and reducing lordosis of the neck during neck movement (Falla et al., 2004; Javanshir et al., 2011; Jull et al., 2008). FHP is characterized by a decrease in the deep neck flexor muscles located on both sides and an increase in surface neck flexion (Kapreli et al., 2008). As a result, this reduces the range of motion of the neck and increases the bending torque of the surface neck flexor muscles (Vasavada et al., 1998). The cervical vertebrae contribute proprioceptive sense input. The proprioceptive sensing of the cervical vertebrae transmits information to correct misalignment and plays an important role in postural control. In addition, it reacts sensitively to the fine movement of the head by acting in coordination with sensing from the
${ }^{*}$ Corresponding author: Yun-Hee Sung (D) https://orcid.org/0000-0002-4877-9784 Department of Physical Therapy, College of Health Sciences, Kyungnam University, 7 Kyungnamdaehak-ro, Masanhappo-gu, Changwon 51767, Korea

E-mail: sungpt97@kyungnam.ac.kr

Received: January 20, 2020 / Accepted: February 27, 2020
This is an Open Access article distributed under the terms of the Creative Commons Attribution Non-Commercial License (https://creativecommons.org/licenses/by-nc/4.0/) which permits unrestricted non-commercial use, distribution, and reproduction in any medium, provided the original work is properly cited. 
vestibular system (Johnson and van Emmerik, 2012). Asymmetric alignment of the head and neck results in errors in the information received as visual and vestibular sensing (Treleaven, 2008). This eventually reduces the balance and increases the risk of falling and musculoskeletal injuries while performing activities (Lee and Jeong, 2001). In previous studies, severe neck pain has been reported to be associated with decreased balance (Chester, 1991), and decreased joint sensation has been reported to reduce balance control (Brockett et al., 1997).

Previous studies have investigated the relationship between FHP and deep neck muscle area, balance, and intervention methods (Jull et al., 2004; Lee, 2016; Sterling et al., 2003). These studies have been conducted in a variety of contexts and present different results. Therefore, we investigated the physical changes that result from FHP. The purpose of this study was to investigate the effects of FHP on deep neck flexor muscles, proprioception, vestibular function, and static balance.

\section{MATERIALS AND METHODS}

\section{Participants}

This study was conducted on 22 healthy male and female adults. The criteria for selection were (a) no visual impairment, (b) no musculoskeletal disease, (c) no arthritis or other inflammatory disease, and (d) no neck pain. The exclusion criteria were (a) those who had trauma or surgery within the past 6 months, and (b) those who had vestibular or neurological disorders (Table 1). Prior to the experiment, the research purpose and procedure were fully explained to the selected participants. The participants were randomly assigned to one of two groups. The experimental group maintained a craniovertebral angle (CVA) of $<49^{\circ}$ and the control group maintained a CVA of $>50^{\circ}$ watching the smartphone for $40 \mathrm{~min}$. All procedures followed were in accordance with Helsinki Declaration. Information on the purpose and method of the present study was explained to the subjects, and Informed consent was obtained from them.

Table 1. General characteristics of participants

\begin{tabular}{lcc}
\hline Variable & Experimental group $(\mathrm{n}=11)$ & Control group $(\mathrm{n}=11)$ \\
\hline Height $(\mathrm{cm})$ & $171.91 \pm 7.98$ & $167.18 \pm 4.92$ \\
Weight $(\mathrm{kg})$ & $66.91 \pm 12.96$ & $61.09 \pm 8.73$ \\
Age $(\mathrm{yr})$ & $21.82 \pm 1.78$ & $21.36 \pm 1.43$ \\
Sex & & \\
Male & 7 & 5 \\
Female & 4 & 6 \\
\hline
\end{tabular}

Values are presented as mean \pm standard deviation or number.

\section{Craniovertebral angle}

To measure the CVA, participants were imaged at a distance of $1.5 \mathrm{~m}$ from their sitting position, and the participant's shoulder and the camera height were placed at the same level (Moghadam et al., 2018). The CVA was measured using a horizontal line passing through the $\mathrm{C} 7$ spinous process and a line connecting $\mathrm{C} 7$ to the tragus of the ear (Quek et al., 2013). The angle measurement in the captured image was determined using Image J software (ver. 1.46; U.S. National Institutes of Health, Bethesda, MD, USA).

\section{Ultrasonography}

We measured the area of the longus colli and longus capitis muscles of the deep neck flexors. The SonoAce X8 (Samsung Medison, Seoul, Korea) was used for the measurements. The area of the deep neck flexor muscles was measured after sitting in-position for 40 min in FHP or normal head posture after watching a smartphone, keeping the posture state. Using the Image J software, the area of the deep neck flexor muscles was measured (in $\mathrm{mm}^{2}$ ) using a 7.5 $\mathrm{MHz}$ linear probe placed vertically at a distance of $3 \mathrm{~cm}$ from the trachea. Measurements were taken two times before and after each measurement, and the mean value was used (Fig. 1).

\section{Cervical joint position sense}

To examine the proprioceptive sensing of the cervical vertebrae, each participant wore a headband with a laser pointer affixed to it

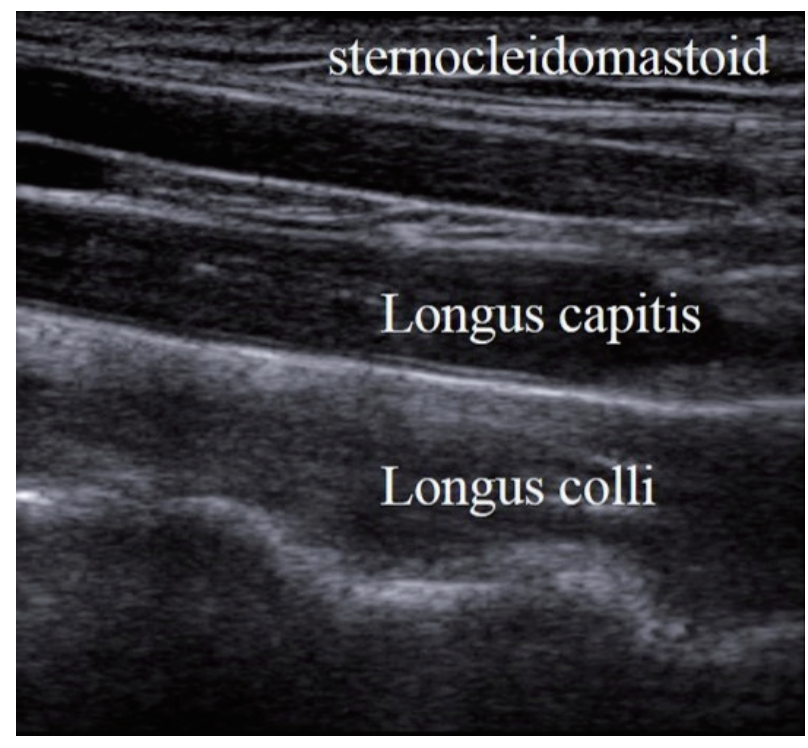

Fig. 1. Ultrasonography imaging of the deep cervical flexor muscles (longus colli and longus capitis). The area of the deep cervical flexor muscles was measured with the forward head posture maintained (experimental) or with the normal head posture (control) maintained. 
on their head. The participant was directed to stand $90 \mathrm{~cm}$ away from the wall and focus on the center point of the joint position error target. The participant closed their eyes. The evaluator arbitrarily rotates the head left or right, then the participant is instructed to return (reorient back) to the center of the error target. At this time, the color of the circle nearest to the center point of the joint position error target was 3 points, and the color of the circle farthest from the center point was 1 point. A score was assigned according to the location to which they returned on reorienting. Measurements were made 5 times for left and right, respectively, and mean values were used.

\section{Subjective visual vertical test and subjective visual horizontal test}

This is the classic test method for measuring vestibular sensing. The test uses a bucket that is larger than $25 \mathrm{~cm}$ in diameter, with a black line drawn on the inside bottom of the bucket. On the outside bottom of the bucket, there is a goniometer scale attached so that the bucket can rotate. The reading of 0 on the goniometer should be aligned with true vertical or true horizontal orientation, and weighted to keep from rotating along with the bucket. While the participant's head is inside, the bucket is rotated, and the participant indicates when they believe that the line is perfectly vertical (or horizontal, respectively), the weighted scale informs the size of the angle off of the vertical or horizontal line.

\section{Romberg test with Wii balance board}

We used the Wii balance board (Nintendo Co. Ltd., Kyoto, Japan) to analyze the static balance of the subjects. The measured static balance analysis was performed using Balancia software (ver. 2.0; Mintosys, Seoul, Korea). The collected data is transmitted to a computer device connected via Bluetooth. The participants were

Table 2. Comparison of the area of deep neck flexor muscles after smartphone use $\left(\mathrm{mm}^{2}\right)$

\begin{tabular}{lrrr}
\hline Varible & Experimental & Control & $P$-value \\
\hline Longus capitis & & & \\
Pre & $21.96 \pm 4.47$ & $22.85 \pm 3.99$ & 0.628 \\
Post & $20.71 \pm 4.44$ & $21.39 \pm 4.31$ & 0.719 \\
Post-pre & $-1.25 \pm 4.93$ & $-1.45 \pm 3.17$ & 0.907 \\
Longus colli & & & \\
Pre & $24.27 \pm 5.24$ & $22.39 \pm 6.08$ & 0.446 \\
Post & $24.54 \pm 5.26$ & $23.76 \pm 1.74$ & 0.645 \\
Post-pre & $0.26 \pm 5.55$ & $1.36 \pm 5.19$ & 0.636 \\
\hline
\end{tabular}

Values are presented as mean \pm standard deviation. asked to stand upright on the Wii balance board, with both arms relaxed. Participant eyes were open, then closed, for $30 \mathrm{sec}$ each. Measurements were made three times before and after the experiment, and the mean value was used.

\section{Statistical analysis}

The Kolmogorov-Smirnov test was used to investigate the normal distribution of the variables. The independent $t$-test was used to examine the effects between groups. The level of significance was set as $P<0.05$.

\section{RESULTS}

\section{Changes in deep neck flexor muscles area}

The area of the deep neck flexor muscles and the extent of change (post-pre) in the deep neck flexor muscle area showed no significant difference between the two groups (Table 2).

\section{Changes in proprioception}

For the task of returning their head to the original position, there was a significant difference in the posttest $(P<0.05)$ after having their head turned to the right, however, as to the same reorienting task after having their head turned to the left, there was no significant difference between the groups in the posttest. The extent of change (post-pre) in the cervical joint position sensing did show a significant difference between the two groups $(P<0.05)$ (Table 3).

\section{Changes in vestibular function}

The subjective visual vertical (SVV) test, subjective visual horizontal (SVH) test, and the extent of change (post-pre) in the SVH test and SVV test showed no significant difference between the

Table 3. Comparison of the cervical joint position sense after smartphone use (cm)

\begin{tabular}{lrrr}
\hline Variable & Experimental group & Control group & $P$-value \\
\hline Centered after turning to the right & & \\
Pre & $1.77 \pm 0.88$ & $1.68 \pm 0.47$ & 0.753 \\
Post & $1.37 \pm 0.92$ & $2.06 \pm 0.36$ & $0.041^{*}$ \\
Post-pre & $-0.04 \pm 0.66$ & $0.37 \pm 0.51$ & $0.006^{*}$ \\
Centered after turning to the left & & \\
Pre & $1.83 \pm 0.74$ & $1.78 \pm 0.45$ & 0.856 \\
Post & $1.82 \pm 0.72$ & $2.22 \pm 0.49$ & 0.140 \\
Post-pre & $-0.01 \pm 0.22$ & $0.44 \pm 0.32$ & $0.001^{*}$ \\
\hline
\end{tabular}

Values are presented as mean \pm standard deviation. ${ }^{*} P<0.05$, statistically significant difference. 
Table 4. Comparison of the SVH test and SW test after smartphone use (cm)

\begin{tabular}{lccc}
\hline Test & Experimental group & Control group & $P$-value \\
\hline SVH test & & & \\
Pre & $2.24 \pm 1.00$ & $2.12 \pm 1.11$ & 0.792 \\
Post & $2.30 \pm 1.33$ & $2.42 \pm 1.30$ & 0.832 \\
Post-pre & $0.06 \pm 0.98$ & $0.30 \pm 2.14$ & 0.736 \\
SW test & & & \\
Pre & $1.69 \pm 1.90$ & $2.03 \pm 1.49$ & 0.651 \\
Post & $2.42 \pm 1.27$ & $2.75 \pm 1.60$ & 0.595 \\
Post-pre & $0.72 \pm 1.29$ & $0.72 \pm 2.11$ & 0.998 \\
\hline
\end{tabular}

Values are presented as mean \pm standard deviation.

SW, subjective visual vertical; SVH, subjective visual horizontal.

two groups (Table 4).

\section{Changes in static balance}

Sway velocity, sway path length, sway area, and the extent of change (post-pre) in the sway velocity, sway path length, and sway area showed no significant difference between the two groups (Table 5).

\section{DISCUSSION}

Excessive use of smartphones for long periods of time can lead to decreased postural control and FHP (Kim and Kim, 2019). The purpose of this study was to determine the effect of FHP and normal head posture on deep neck flexor muscles, proprioception, vestibular function, and static balance when watching a smartphone.

In the present study, there was no significant difference in the deep neck flexor area between the two groups. A persistent poor head posture causes excessive joint and muscle loading and affects deep cervical muscle weakness, resulting in a change in the cervical region (Harman et al., 2005; Szeto et al., 2002; Yong et al., 2015). In a study of the correlation between the cranio-vertebral angle and longus colli area of FHP, the longus colli thickness decreased as the angle decreased. This result suggested that the FHP changes the position of the head in the sitting position and causes disuse of the deep neck flexor muscles in daily life (Ishida et al., 2015). The area of the deep neck flexor muscles was compared when the cranio-cervical flexion test was performed in a group of females with FHP and in a normal head posture group. There was no difference in the area at rest or during the cranio-cervical flexion test between the two groups. This result is due to the fact that the participants maintained FHP for a short period of time and short-term-induced tension changes cannot affect the deep neck
Table 5. Comparison of the Romberg test with Wii balance board after smartphone use

\begin{tabular}{|c|c|c|c|}
\hline Variable & Experimental group & Control group & $P$-value \\
\hline \multicolumn{4}{|c|}{ Sway velocity (cm/sec) } \\
\hline \multicolumn{4}{|c|}{ Eyes closed } \\
\hline Pre & $3.14 \pm 0.54$ & $3.18 \pm 0.52$ & 0.859 \\
\hline Post & $3.13 \pm 0.90$ & $3.06 \pm 0.60$ & 0.837 \\
\hline Post-pre & $-0.01 \pm 0.54$ & $-0.11 \pm 0.40$ & 0.602 \\
\hline \multicolumn{4}{|l|}{ Eyes open } \\
\hline Pre & $2.66 \pm 0.68$ & $2.70 \pm 0.34$ & 0.879 \\
\hline Post & $2.68 \pm 0.50$ & $2.67 \pm 0.31$ & 0.968 \\
\hline Post-pre & $0.01 \pm 0.49$ & $-0.02 \pm 0.35$ & 0.830 \\
\hline \multicolumn{4}{|c|}{ Sway path length (cm) } \\
\hline \multicolumn{4}{|c|}{ Eyes closed } \\
\hline Pre & $94.28 \pm 16.18$ & $95.49 \pm 15.72$ & 0.861 \\
\hline Post & $94.01 \pm 27.13$ & $92.00 \pm 18.13$ & 0.840 \\
\hline Post-pre & $-0.26 \pm 16.36$ & $-3.49 \pm 12.11$ & 0.605 \\
\hline \multicolumn{4}{|l|}{ Eyes open } \\
\hline Pre & $80.02 \pm 20.46$ & $81.02 \pm 10.25$ & 0.886 \\
\hline Post & $80.33 \pm 15.17$ & $80.20 \pm 9.41$ & 0.982 \\
\hline Post-pre & $0.31 \pm 14.80$ & $-0.81 \pm 10.57$ & 0.839 \\
\hline \multicolumn{4}{|c|}{ Sway area $\left(\mathrm{cm}^{2}\right)$} \\
\hline \multicolumn{4}{|c|}{ Eyes closed } \\
\hline Pre & $12.78 \pm 7.44$ & $9.52 \pm 6.58$ & 0.289 \\
\hline Post & $13.57 \pm 14.92$ & $7.38 \pm 2.74$ & 0.191 \\
\hline Post-pre & $0.78 \pm 9.03$ & $-2.13 \pm 5.59$ & 0.372 \\
\hline \multicolumn{4}{|l|}{ Eyes open } \\
\hline Pre & $5.87 \pm 4.15$ & $4.67 \pm 2.12$ & 0.408 \\
\hline Post & $6.96 \pm 4.75$ & $6.14 \pm 3.12$ & 0.638 \\
\hline Post-pre & $1.09 \pm 4.37$ & $1.47 \pm 3.65$ & 0.827 \\
\hline
\end{tabular}

Values are presented as mean \pm standard deviation.

flexor muscles (Moghadam et al., 2018). Bokaee et al. (2017) measured the thickness of the cervical muscles in a sitting position on females with and without FHP. There was a significant difference between the two groups in sternocleidomastoid muscle, but there was no significant difference between the two groups in longus colli muscle. This is in agreement with the results of the present study. The area of the deep neck flexor muscles tended to decrease, though not significantly, due to the transiently induced FHP. Future research will be needed to observe changes over long periods of time.

Balance is affected by visual, proprioception, inner ear, and vestibular sensing, cerebellar function, age, heartbeat or respiration, and various musculoskeletal disorders (Di Fabio, 1995). Among them, proprioception provides sensory feedback to the nervous system in the body, contributing to maintaining optimal body alignment. Neck muscles have higher muscle spindle density 
than other body muscles. Therefore, the neck muscles play a key role in providing the proprioceptive sensory information (Treleaven, 2008). In the results of the present study, there was a significant difference between the two groups when participants needed to rotate (reorient) their head back to center after having it turned to the right. There was a significant difference in the extent of change of joint position sensing between the two groups. The FHP showed a higher error than the normal posture group, and the joint position sensing was reduced. Yong et al. (2015) reported a correlation between head posture and proprioception in 72 subjects. The CVA had a negative correlation with position sensing. Lee et al. (2014) reported that FHP had a higher error value when observing cervical position sensing for FHP and normal head posture. These results suggest that the change in the length of the neck muscles caused by the FHP has a negative effect on the muscle spindle activity involved in proprioception, resulting in a decrease in joint position sensing. In the present study, the induced FHP tended to decrease, but not significantly, the deep neck muscle area, resulting in a higher error value in the experimental group due to adverse effects on the proprioceptive sensation.

The vestibular system provides information related to head movement and direction (Forbes et al., 2016). The sensing of head posture and body alignment are influenced by sensory information coming from the vestibular system and proprioception sensing located in the neck (Armstrong et al., 2008). In particular, the upper cervical spine contains many muscle spindles and more connections with the visual and vestibular systems, contributing more to reflex activity than other parts of the cervical spine (Kulkarni et al., 2001; Liu et al., 2003). Proprioceptive alteration in the neck muscles can lead to the asymmetrical function of the vestibulo-ocular reflex (Padoan et al., 1998). Therefore, in this study, we assumed that an increase in the lordotic curve of the upper cervical spine via FHP could affect vestibular sensing. In this study, there was no significant difference between the groups in SVH and SVV tests for vestibular function. These results suggest that the subjects of this study were not impaired by the vestibular system, and we think that the transiently induced FHP does not affect the vestibular function because it uses visual, proprioception, and vestibular sensing to maintain posture.

Postural sway measurements are most commonly used to evaluate balance and provide information about sensory changes as a result of changes in standing surface or field of view (Kim et al., 2014). In the present study, there was no difference in sway values between the groups when the eyes were opened and closed. In the study of Silva and Johnson (2013), there was no difference between the groups when measuring balance (total distance, total sway area, and mean velocity) for $30 \mathrm{sec}$ divided into a natural head posture group and an induced exaggerated FHP group. They reported that the postural control system of young healthy participants adapted to the exaggerated FHP. Dornan et al. (1978) reported that visual recognition is an essential element in maintaining balance and posture in static conditions. In a cross-sectional study by Lee (2016) of the static and dynamic balance of the FHP group and the normal head posture group, the difference in static balance was higher among those who closed their eyes than those who opened their eyes, indicating that vision plays an important role in balance control. Kang et al. (2012) found that there were no significant differences in the conditions in normal body sensory, visual, and vestibular systems in a study of the effects of the FHP on postural balance in a long-time computer-based worker. However, if the sensing for balance control is blocked, the posture control ability decreased. Based on the results of previous studies, the results of this study also suggest that FHP applied as a single short-duration event in the experimental group did not affect the balance by altering the posture control system. Also, when the sensing for balance control was blocked, through limiting proprioception sensing due to FHP, it is thought that it will affect balance control.

According to the results of this study, proprioception was significantly different when watching the smartphone for $40 \mathrm{~min}$ with induced FHP, but deep neck flexor muscles, static balance, and vestibular function were not significantly different. The most important factor affecting the induced FHP applied as a single short-duration event is thought to be proprioception. Limitations of this study include (a) healthy people and a small number of subjects, therefore there is a limit to generalizing the contents. (b) For the FHP, the smartphone usage time was $40 \mathrm{~min}$ and one time. (c) Only deep neck flexor muscles were measured by ultrasonography. Future studies should endeavor to address these limitations.

\section{CONFLICT OF INTEREST}

No potential conflict of interest relevant to this article was reported.

\section{REFERENCES}

Armstrong B, McNair P, Taylor D. Head and neck position sense. Sports Med 2008;38:101-117.

Bokaee F, Rezasoltani A, Manshadi FD, Naimi SS, Baghban AA, Azimi H. 
Comparison of cervical muscle thickness between asymptomatic women with and without forward head posture. Braz J Phys Ther 2017;21: 206-211.

Braun BL, Amundson LR. Quantitative assessment of head and shoulder posture. Arch Phys Med Rehabil 1989;70:322-329.

Brockett C, Warren N, Gregory JE, Morgan DL, Proske U. A comparison of the effects of concentric versus eccentric exercise on force and position sense at the human elbow joint. Brain Res 1997;771:251-258.

Burgess-Limerick R, Plooy A, Ankrum DR. The effect of imposed and self-selected computer monitor height on posture and gaze angle. Clin Biomech (Bristol, Avon) 1998;13:584-592.

Chester JB Jr. Whiplash, postural control, and the inner ear. Spine (Phila Pa 1976) 1991;16:716-720.

Di Fabio RP. Sensitivity and specificity of platform posturography for identifying patients with vestibular dysfunction. Phys Ther 1995;75: 290-305.

Dornan J, Fernie GR, Holliday PJ. Visual input: its importance in the control of postural sway. Arch Phys Med Rehabil 1978;59:586-591.

Eltayeb S, Staal JB, Hassan A, de Bie RA. Work related risk factors for neck, shoulder, and arms complaints: a cohort study among Dutch computer office workers. J Occup Rehabil 2009;19:315-322.

Falla D, Jull G, Edwards S, Koh K, Rainoldi A. Neuromuscular efficiency of the sternocleidomastoid and anterior scalene muscles in patients with chronic neck pain. Disabil Rehabil 2004;26:712-717.

Forbes PA, Luu BL, Van der Loos HF, Croft EA, Inglis JT, Blouin JS. Transformation of vestibular signals for the control of standing in humans. J Neurosci 2016;36:11510-11520.

Hanten WP, Lucio RM, Russell JL, Brunt D. Assessment of total head excursion and resting head posture. Arch Phys Med Rehabil 1991;72: $877-880$.

Harman K, Hubley-Kozey CL, Butler H. Effectiveness of an exercise program to improve forward head posture in normal adults: a randomized controlled 10-week trial. J Man Manipul Ther 2005;13:163-176.

Ishida H, Suehiro T, Kurozumi C, Ono K, Ando S, Watanabe S. Correlation between neck slope angle and deep cervical flexor muscle thickness in healthy participants. J Bodyw Mov Ther 2015;19:717-721.

Javanshir K, Mohseni-Bandpei MA, Rezasoltani A, Amiri M, Rahgozar M. Ultrasonography of longus colli muscle: a reliability study on healthy subjects and patients with chronic neck pain. J Bodyw Mov Ther 2011; 15:50-56.

Johnson MB, Van Emmerik R EA. Effect of head orientation on postural control during upright stance and forward lean. Motor Control 2012; 16:81-93.

Jull G, Kristjansson E, Dall'Alba P. Impairment in the cervical flexors: a comparison of whiplash and insidious onset neck pain patients. Man
Ther 2004;9:89-94.

Jull GA, O’Leary SP, Falla DL. Clinical assessment of the deep cervical flexor muscles: the craniocervical flexion test. J Manipulative Physiol Ther 2008;31:525-533.

Kang JH, Park RY, Lee SJ, Kim JY, Yoon SR, Jung KI. The effect of the forward head posture on postural balance in long time computer based worker. Ann Rehabil Med 2012;36:98-104.

Kapreli E, Vourazanis E, Strimpakos N. Neck pain causes respiratory dysfunction. Med Hypotheses 2008;70:1009-1013.

Kim EK, Kim SG. Forward head posture (FHP) angle and plantar pressure resulting from oscillatory stimulation training of the shoulder joint: a randomized controlled trial. J Back Musculoskelet Rehabil 2019;32: $37-42$.

Kim HS, Lee CW, Lee IS. Comparison between the effects of horseback riding exercise and trunk stability exercise on the balance of normal adults. J Phys Ther Sci 2014;26:1325-1327.

Kulkarni V, Chandy MJ, Babu KS. Quantitative study of muscle spindles in suboccipital muscles of human foetuses. Neurol India 2001;49:355359.

Larsson B, Søgaard K, Rosendal L. Work related neck-shoulder pain: a review on magnitude, risk factors, biochemical characteristics, clinical picture, and preventive interventions. Best Pract Res Clin Rheumatol 2007;21:447-463.

Lee CM, Jeong EH, Freivalds A. Biomechanical effects of wearing highheeled shoes. Int J Ind Ergon 2001;28:321-326.

Lee JH. Effects of forward head posture on static and dynamic balance control. J Phys Ther Sci 2016;28:274-277.

Lee MY, Lee HY, Yong MS. Characteristics of cervical position sense in subjects with forward head posture. J Phys Ther Sci 2014;26:1741-1743.

Liu JX, Thornell LE, Pedrosa-Domellöf F. Muscle spindles in the deep muscles of the human neck: a morphological and immunocytochemical study. J Histochem Cytochem 2003;51:175-186.

Moghadam RE, Rahnama L, Karimi N, Amiri M, Rahnama M. An ultrasonographic investigation of deep neck flexor muscles cross-sectional area in forward and normal head posture. J Bodyw Mov Ther 2018;22: 643-647.

Padoan S, Karlberg M, Fransson PA, Magnusson M. Passive sustained turning of the head induces asymmetric gain of the vestibulo-ocular reflex in healthy subjects. Acta Otolaryngol 1998;118:778-782.

Quek J, Pua YH, Clark RA, Bryant AL. Effects of thoracic kyphosis and forward head posture on cervical range of motion in older adults. Man Ther 2013;18:65-71

Silva AG, Johnson MI. Does forward head posture affect postural control in human healthy volunteers? Gait Posture 2013;38:352-353.

Sterling M, Jull G, Vicenzino B, Kenardy J, Darnell R. Development of 
motor system dysfunction following whiplash injury. Pain 2003;103: 65-73.

Straker L, Burgess-Limerick R, Pollock C, Coleman J, Skoss R, Maslen B. Children's posture and muscle activity at different computer display heights and during paper information technology use. Hum Factors 2008;50:49-61.

Szeto GP, Straker L, Raine S. A field comparison of neck and shoulder postures in symptomatic and asymptomatic office workers. Appl Ergon 2002;33:75-84.
Treleaven J. Sensorimotor disturbances in neck disorders affecting postural stability, head and eye movement control. Man Ther 2008;13: 2-11.

Vasavada AN, Li S, Delp SL. Influence of muscle morphometry and moment arms on the moment-generating capacity of human neck muscles. Spine (Phila Pa 1976) 1998;23:412-422.

Yong MS, Lee HY, Ryu YU, Lee MY. Effects of craniocervical flexion exercise on upper-limb postural stability during a goal-directed pointing task. J Phys Ther Sci 2015;27:2005-2007. 